\title{
Fibroblast Growth Factor Receptor 3 (FGFR3) - Analyses of the S249C mutation and protein expression in primary cervical carcinomas
}

\author{
Haiyan Dai ${ }^{\text {a }}$, Ruth Holm ${ }^{\text {b }}$, \\ Gunnar B. Kristensen ${ }^{\mathrm{c}}$, Vera M. Abeler ${ }^{\mathrm{b}}$, \\ Anne-Lise Børresen-Dale a and Åslaug Helland ${ }^{\mathrm{a}, *}$ \\ a Department of Genetics, Institute for Cancer \\ Research, The Norwegian Radium Hospital, N-0310 \\ Oslo, Norway \\ ${ }^{\mathrm{b}}$ Department of Pathology, Institute for Cancer \\ Research, The Norwegian Radium Hospital, N-0310 \\ Oslo, Norway \\ ${ }^{\mathrm{c}}$ Department of Gynaecological Oncology, Institute \\ for Cancer Research, The Norwegian Radium \\ Hospital, N-0310 0slo, Norway
}

Received 15 June 2001

Accepted 11 October 2001

Fibroblast growth factor receptor 3 (FGFR3) seems to play an inhibitory role in bone development, as activating mutations in the gene underlie disorders such as achondroplasia and thanatophoric dysplasia. Findings from multiple myeloma (MM) indicate that FGFR3 also can act as an oncogene, and mutation of codon 249 in the fibroblast growth factor receptor 3 (FGFR3) gene was recently detected in $3 / 12$ primary cervical carcinomas. We have analysed 91 cervical carcinomas for this specific S249C mutation using amplification created restriction site methodology (ACRS), and detected no mutations. Immunohistochemistry was performed on 73 of the tumours. Reduced protein staining was seen in $43(58.8 \%)$ samples. Six of the tumours $(8.2 \%)$ revealed increased protein staining compared with normal cervical tissue. These patients had a better prognosis than those with reduced or normal levels, although not statistically significant.

\footnotetext{
${ }^{*}$ Corresponding author: Åslaug Helland, Department of Genetics, Institute for Cancer Research, The Norwegian Radium Hospital, N-0310 Oslo, Norway. Tel. +47 2293 4424; Fax: +47 2293 4440; E-mail: ahelland@labmed.uio.no.
}

This report weakens the hypothesis of FGFR3 as an oncogene of importance in cervical carcinomas.

Keywords: FGFR3, S249C mutation, IHC, cervical carcinomas, FGFR3 protein levels

Abbreviations: FGFR, fibroblast growth factor receptor; FGF, fibroblast growth factor; PCR, polymerase chain reaction; IHC, immunohistochemistry; bp, base pair; ACRS, amplification created restriction site.

\section{Introduction}

Carcinoma of the uterine cervix is the third most common malignancy among women world-wide [11]. Human papillomavirus (HPV) has been established as a causative agent in cervical carcinogenesis, and HPV DNA is found in virtually all carcinomas [2]. Most HPV infections resolve spontaneously, and additional factors are required for malignant transformation to occur. Fibroblast growth factors (FGFs) comprise a family of structurally related polypeptides that are involved in diverse processes including embryonic development, cell proliferation, motility and differentiation, as well as in autonomous tumour growth and vascularisation $[1,8]$ and at least four distinct fibroblast growth factor receptors (FGFRs) have been identified (FGFR1-4) [9]. FGFRs are normally inactive in the absence of an FGF ligand.

The FGFR3 gene is located in chromosome region 4p16.3 [17] and contains 19 exons spanning $16.5 \mathrm{~kb}$ [13]. Dominant, activating FGFR3 mutations have been implicated in skeletal disorders as achondroplasia, hypochondroplasias and thanatophoric dysplasia (for ref., see [12]). It is proposed that one function of FGFR3 is to limit osteogenesis, and that mutations found in human skeletal disorders are gain-of- 
function mutations. Deng et al. found that recessive loss-of-function mutation in FGFR3 - / - mice gave a phenotype characterised by overgrowth [6].

Recent findings have indicated an oncogenic role for FGFR3 in multiple myeloma (MM). The translocation $\mathrm{t}(4 ; 14)(\mathrm{p} 16.3 ; \mathrm{q} 32,3)$ is suggested to occur in $25 \%$ of MM, and is found to be associated with high levels of FGFR3 mRNA and protein [5,14]. Chesi et al. have proposed that following the $\mathrm{t}(4 ; 14)$ translocation, subsequent somatic mutation of the FGFR3 gene frequently generates an FGFR3 protein that is active in the absence of ligand [5]. However, mutations have so far only rarely been found in MM tumours.

Most recently, Cappellen and co-workers reported FGFR3 mutations in 9/26 human bladder carcinomas and in $3 / 12$ cervical carcinomas [3]. The mutations in the cervical carcinomas were all missense mutations in codon 249 resulting in a substitution of serine to cystein. This mutation has also been found in patients with thanatophoric dysplasia [16]. Cappellen and coworkers detected FGFR3 RNA expression in normal cervical epithelia, and also in $27 / 29$ cervical carcinomas.

In this study, we have analysed 91 cervical carcinomas for the S249C mutation; 73 of them were also available for protein expression analysis by immunohistochemistry. Association to survival was also investigated.

\section{Materials and methods}

\subsection{Material}

Ninety-one patients with primary cervical carcinoma admitted to The Norwegian Radium Hospital during the period from 1989 to 1991 were selected for this study. Mean age at diagnosis was 53 years (range, 22-90). The median observation-time of living patients was 100 months. Primary tumour biopsies were fresh frozen and stored in frozen condition $\left(-80^{\circ} \mathrm{C}\right)$ until analysis. The approximate percentage of tumour cells in the fresh-frozen samples was visually estimated from Hematoxylin-Eosin (HE) stained sections. All samples included in this study had at least $20 \%$ tumour tissue. Tumour DNA was isolated by Nucleic Acid Extractor (Applied Biosystem, Foster City, CA) using phenol/chloroform extraction followed by ethanol precipitation. Formalin-fixed paraffin-embedded tissue from 10 biopsies from normal cervical epithelium (patients with benign uterine leiomyomas) and 73 cases with cervical carcinoma were available for immunohistochemical analysis.

\subsection{Mutation analysis}

Amplification created restriction site methodology (ACRS) was used to detect the S249C mutation [7]. Parts of intron 6 and exon 7 were amplified by PCR giving a product of 101 basepairs. The oligonucleotide primers used were $5^{\prime}$-AGCGTCATCTGCCCCCACAGACCGC-3', reverse 5-'GGAACTCCACGTCGCTGCCCAGCAC $-3^{\prime}$. The underlined base cytosine $(\mathrm{C})$ is changed from the original base guanine $(\mathrm{G})$, resulting in a restriction site for the enzyme BsrBI (New England BioLabs Inc, Beverly, MA) in the wild type sequence (CCGCTC). A template with the S249C mutation would give the sequence CCGCTG which is not cut by the enzyme. PCR was performed in $25 \mu 1$ reaction volumes containing $50 \mathrm{ng}$ of template DNA, $1 \times$ PCR buffer II (Perkin-Elmer, Branchburge, NJ, USA), $25 \mathrm{mM}$ magnesium chloride, $2.5 \mathrm{mM}$ dNTP, 20 pmol of each primer and 5 units of Taq polymerase (AmpliTaq, Cetus, USA). The reaction was initiated with denaturation at $94^{\circ} \mathrm{C}$ for $3 \mathrm{~min}$ followed by 37 cycles at $94^{\circ} \mathrm{C}(15 \mathrm{~s}), 64.5^{\circ} \mathrm{C}(15 \mathrm{~s}), 72^{\circ} \mathrm{C}(30 \mathrm{~s})$, and a final extension step at $72^{\circ} \mathrm{C}$ for $8 \mathrm{~min}$. After amplification, $10 \mu \mathrm{l}$ of final products were digested with 4 units BsrBI and size-fractionated in $7.5 \%$ polyacrylamide gels. The products (101 bp) were cleaved into a $77 \mathrm{bp}$ and a $24 \mathrm{bp}$ fragment if no mutation was present.

To ensure the ACRS method's capability to detect the S249C mutation if present, a control fragment with the S249C mutation was created by PCR using a modified $5^{\prime}$ primer containing the mutation (underlined) (CTGAGCGTCATCTGCCCCCACAGAGCGCTGCCC). In addition, DNA from 7 tumour samples and one normal control DNA was submitted to direct sequencing. Briefly, the samples were amplified and purified using MicroSpin Columns (Pharmacia Biotech, Uppsala, Sweden). The products were submitted to sequencing using an automated 373 DNA Sequencer and Big Dye (PE Applied Biosystems, Foster City, USA ) according to the suppliers protocol. Two independent observers manually read the sequences.

\subsection{Immunohistochemistry}

Paraffin embedded tissues were immunostained using the biotin-streptavidin-peroxidase method (Supersensitive Immunodetection system, LP 000-uL, Biogenex, CA, USA). Deparaffinized sections were microwaved in $10 \mathrm{mM}$ citrate buffer $(\mathrm{pH} \mathrm{6.0)}$ and then treated with $1 \%$ hydrogen peroxide. Immunostaining was performed with polyclonal rabbit anti-FGFR3 
(C-15, Santa Cruze Biotechnology Inc, CA, USA), diluted $1: 75(2.6 \mu \mathrm{g} \mathrm{IgG/ml})$ for 1 hour at room temperature. The sections were incubated with biotinlabelled secondary antibody $(1: 30)$ and streptavidinperoxidase $(1: 30)$ for 20 minutes. After staining for 5 minutes using $0.05 \%$ 3, $3^{\prime}$-diaminobenzidine tetrahydrochloride freshly prepared in $0.05 \mathrm{M}$ Tris buffer (pH 7.6) containing $0.024 \% \mathrm{H}_{2} \mathrm{O}_{2}$, the sections were counterstained with haematoxylin, dehydrated and mounted in Diatex. All series included normal pancreas as positive control. Negative controls included substitution of primary antibody with normal rabbit $\mathrm{IgG}$ at a concentration of $2.6 \mu \mathrm{g} \mathrm{IgG/ml}$. All controls gave satisfactory results.

The immunostaining results was graded semiquantitatively by two of the authors independently according to both extent of staining (percentage of positive tumour cells: $<10: 1 ; 10-50 \%: 2 ;>50 \%: 3)$ and intensity (absent/weak: 1; moderate: 2; strong: 3). The scoring results of intensity and extent were multiplied to give a composite score (1-9) for each tumour. Composite scores from 1 to 3 were defined as marked reduction or absence of FGFR3 protein expression. Scores from 4 to 6 were considered normal protein levels, and more than 6 as high protein levels.

\subsection{Statistics}

Progression-free survival was defined as the interval between diagnosis and progression or death of disease. The method of Kaplan and Meier and the log rank test were used for univariate estimation of survival rate. The Statistical Package for Social Science (SPSS) was used for the survival analysis. Statistical significance was defined when $P<0.05$.

\section{Results}

We have analysed 91 primary cervical carcinomas for the previously reported mutation in codon 249 in the FGFR3 gene. No mutations were found. We also performed PCR using a control DNA fragment with the mutation at codon 249, and the PCR product was not cut confirming the capability of the method to detect the S249C mutation (Fig. 1). In addition, seven cases with cervical carcinoma and one normal control DNA were selected randomly for sequencing. All samples showed wild-type sequence.

Normal cervical epithelium revealed moderate cytoplasmic and membrane FGFR3 protein staining in the

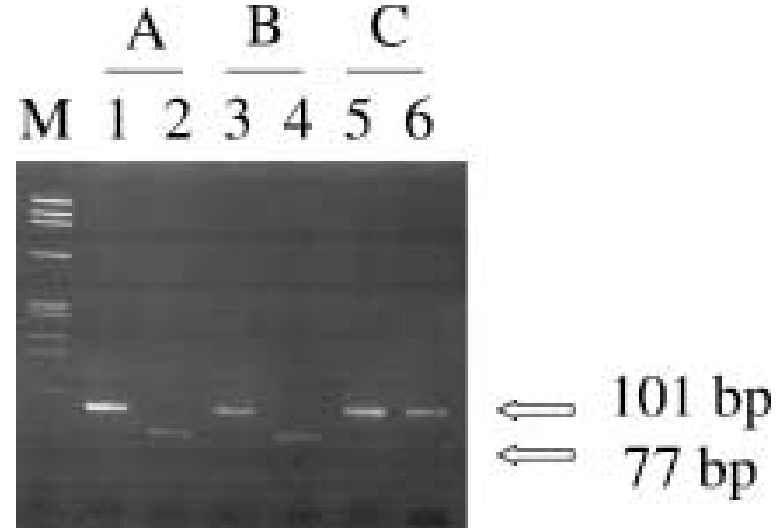

Fig. 1. Detection of the S249C mutation of FGFR3 using amplification created restriction site by PCR. M: HaeIII-digested $\varnothing$ X 174. A: normal blood DNA. B: DNA from cervical carcinomas. C: DNA with an artificially created S249C mutation. Lanes 1, 3 and 5 show the amplification products before BsrBI digestion. Lanes 2, 4 and 6 show the amplification products after BsrBI digestion.

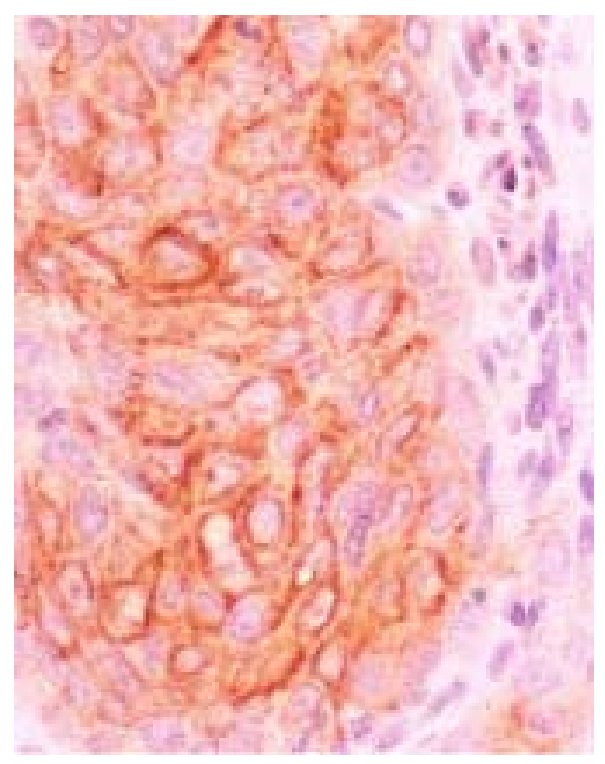

Fig. 2. Expression of FGFR3 protein in cervical carcinoma showing membrane and cytoplasmic staining in most tumor cells.

basal and parabasal layers. Reduced or absent protein staining were detected in $44(60.3 \%)$ of the tumour samples. Twenty-three (31.5\%) tumours revealed protein staining in the normal range with composite scores between $4-6$. Six samples $(8.2 \%)$ showed increased protein levels (Fig. 2). All tumour samples with high protein levels had both cytoplasmic and membrane staining, whereas four tumours with reduced levels had no membrane staining.

FGFR3 protein levels did not influence the progres- 


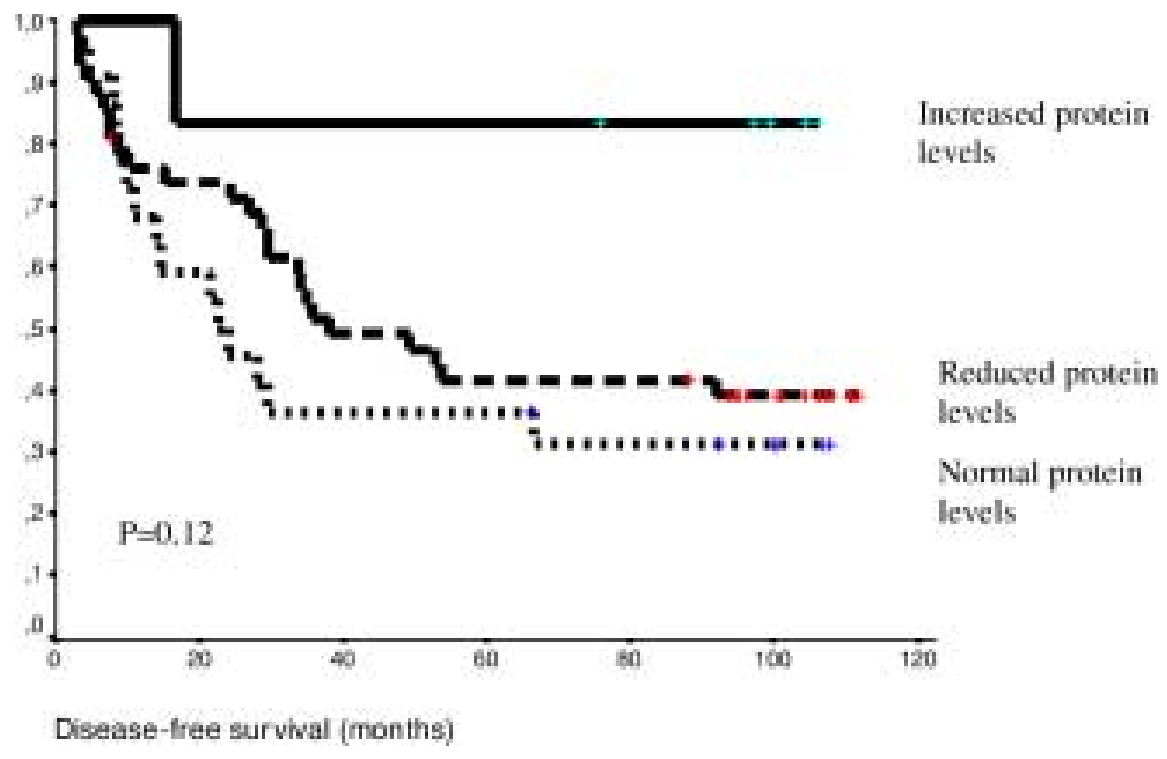

Fig. 3. The univariate analysis shows that overpression of FGFR3 protein is related to a better prognosis, although not statistically significant.

sion-free survival statistically significant (Fig. 3). However, the samples with high protein levels appeared to have a better prognosis, although not statistically significant $(P=0.12)$.

\section{Discussion}

It is well established that different mutations in the FGFR genes lead to receptor activation and underlie several craniosynostosis and dwarfism syndromes [4]. Mouse models have confirmed that the FGFR3 protein is a negative regulator of bone growth, and that common mutations in skeletal disorders are gain of function mutations that lead to reduced proliferation of the chondrocytes [10]. Molecular analysis have shown that expression of the mutation Lys $650 \mathrm{Glu}$ in the FGFR3 receptor (common in TD2), cause activation of stat1, stat5a, stat5b and upregulation of the p16, p18 and p19 cell cycle inhibitors in the chondrocytes. Contrary to this inhibitory role in skeletal disorder, FGFR3 has been proposed as an oncogene in multiple myeloma (MM). In the pathogenesis of these Bcell tumours, translocation to the immunoglobin Heavy (IgH) locus (14q32) seems to occur in 20-60\% of the tumours. The partner chromosome is not always known $(14 q+)$, but recent findings indicate that the translocation $\mathrm{t}(4 ; 14)(\mathrm{p} 16.3$; q32.3) occurs in approximately $25 \%$ of MM tumours. The breakpoint is in a region $70 \mathrm{~kb}$ centromeric to the FGFR3 gene. It involves a new gene MMEST/WHSC1, which fusions with the IgH locus $[4,15]$. Chesi et al. [5] detected increased levels of FGFR3 expression (RNA and protein) in $2 \mathrm{MM}$ cell lines and one primary tumour, containing activating mutations in the FGFR 3 gene in addition to the translocation. This lead to the proposition that FGFR3 was the dysregulated oncogene involved in the oncogenesis of MM.

Regarding epithelial cancer, a recent paper reported activating mutations in FGFR3 in 9/26 bladder and in $3 / 12$ cervical carcinomas. All three mutations found among the cervical carcinomas affected codon 249, changing a serine to a cystein.

In this study, we were not able to confirm a high frequency of this mutation, as we found no S249C mutation among 91 tumours from cervical cancer patients. Other mutations in the FGFR3 gene were not looked for and may be present. However, activating mutations leading to high expression, are unlikely, as the protein levels are reduced in the majority of the tumours in our series.

$\mathrm{Wu}$ and co-workers [18] most recently performed mutational analyses on 51 primary cervical carcinomas encompassing all previously described FGFR3 mutations. They found one S249C mutation, confirming that activating mutations of the FGFR3 gene are rare.

Interestingly, the patients in our study with increased levels of FGFR3 protein seemed to have a better prognosis, although not statistically significant. A growth inhibition, caused by high levels of the FGFR3 protein may have occurred in these tumour cells. Further studies, including a larger cohort of patients, are required 
to assess the role of the FGFR3 protein in cervical carcinogenesis.

\section{Acknowledgements}

The study has been supported by the International Scolarship Section, the Research Council of Norway and CSC (China Scholarship Council) of China. We thank Sigrid Lystad, Phuong Nguyen and Ellen Hellesylt for skilful technical assistance and Vessela Kristensen for valuable discussions.

\section{References}

[1] C. Basilico and D. Moscatelli, The FGF family of growth factors and oncogenes, Adv. Cancer Res. 59 (1992), 115-165.

[2] F.X. Bosch, M.M. Manos, N. Munoz, M. Sherman, A.M. Jansen, J. Peto, M.H. Schiffman, V. Moreno, R. Kurman and K.V. Shah, Prevalence of human papillomavirus in cervical cancer: a worldwide perspective. International biological study on cervical cancer (IBSCC) study group, J. Natl. Cancer. Inst. 87 (1995), 796-802.

[3] D. Cappellen, C.D. Oliveira, D. Ricol and S.G.D. Medona, Frequent activating mutations of FGFR3 in human bladder and cervix carcinomas, Nat. Genet. 23 (1999), 18-20.

[4] M. Chesi, E. Nardini, R.S.C. Lim, K.D. Smith, W.M. Kuehl and P.L. Bergsagel, The $\mathrm{t}(4 ; 14)$ translocation in myeloma dysregulates both FGFR3 and a novel gene, MMSET, resulting in IgH/MMSET hybrid transcripts, Blood 92(9) (1998), 30253034.

[5] M. Chesi, E. Nardini, L.A. Brents, E. Schrock, T. Ried, W.M. Kuehl and P.L. Bergsagel, Frequent translocation t (4; 14)(p16.3; q32.3) in multiple myeloma is association with increased expression and activating mutations of fibroblast growth factor receptor 3, Nat. Genet. 16 (1997), 260-264.

[6] C. Deng, A. Wynshaw-Boris, F. Zhou, A. Kuo and P. Leder, Fibroblast growth factor receptor 3 is a negative regulator of bone growth, Cell 84 (1996), 911-921.

[7] H.G. Eiken, E. Odland, H. Boman, L. Skjelkvåle, L.F. Engebretsen and J. Apold, Application of natural and amplification created restriction sites for the diagnosis of PKU mutations, Nucleic Acids Res. 19 (1991), 1427-1430.

[8] M. Goldfarb, Functions of fibroblast growth factors in vertebrate development, Cytokine Growth Factor Rev. 7(4) (1996), 311-325.
[9] K. Keegan, D.E. Johnson, L.T. Williams and M.J. Hayman, Isolation of an additional member of the fibroblast growth factor receptor family, FGFR3, Proc. Natl. Acad. Sci. USA 88 (1991), 1095-1099.

[10] C. Li, L. Chen, T. Iwata, M. Kitagawa, X.-Y. Fu and C.-X. Deng, A Lys644Glu substitution in fibroblast growth factor receptor 3 (FGFR3) causes dwarfism in mice by activation of STATs and ink4 cell cycle inhibitors, Hum. Molec. Genet. 8 (1999), 35-44.

[11] D.M. Parkin, P. Pisani and J. Ferlay, Estimates of the worldwide incidence of 25 major cancers in 1990, Int. J. Cancer 80 (1999), 827-841.

[12] M.R. Passos-Bueno, W.R. Wilcox, E.W. Jabs, A.L. Sertie, L.G. Alonso and H. Kitoh, Clinical spectrum of fibroblast growth factor receptor mutations, Hum. Mutat. 14 (1999), 115-1125.

[13] A.V. Perez-Castro, J. Wilsom and M.R. Altherr, Genomic organization of the human fibroblast growth factor receptor 3 (FGFR3) gene and comparative sequence analysis with mouse Fgfr3 gene, Genomics 41 (1997), 10-16.

[14] R. Richelda, D. Ronchetti, L. Baldini, L. Cro, L. Viggiano, R. Marzella, M. Rocchi, T. Otsuki, L. Lombardi, A.T. Maiolo and A. Neri, A novel chromosomal translocation $\mathrm{t}(4 ; 14)(\mathrm{p} 16.3 ; \mathrm{q} 32)$ in multiple myeloma involves the fibroblast growth-factor receptor 3 gene, Blood 90(10) (1997), 4062-4070.

[15] I. Stec, T.J. Wright, O.G. van Haeringen, A. Moorman, M.R. Altherr and J.T. den Dunnen, WHSCI, a 90 kb SET domaincontaining gene, expressed in early development and homologous to a drosophila dysmorphy gene maps in the WolfHirschhorn syndrome critical region and is fused to $\operatorname{IgH}$ in t $(4 ; 14)$ multiple myeloma, Hum. Mol. Genet. 7 (1998), 10711082 .

[16] P.L. Tavormina, D.L. Rimoin, D.H. Cohn, Y.-Z. Zhu, R. Shiang and J.J. Wasmuth, Another mutation that results in the substitution of an unpaired cystein residue in the extracellular domain of FGFR3 in thanatophoric dysplasia type I, Hum. Mol. Genet. 4(11) (1995), 2175-2177.

[17] L.M. Thompson, S. Plummer, M. Schalling, M.R. Altherr, J.F. Gusella, D.E. Housman and J.J. Wasmuth, A gene encoding a fibroblast growth factor receptor isolated from the Huntington disease gene region of chromosome 4, Genomics 11 (1991), 1133-1142.

[18] R. Wu, D. Conolly, C. Ngelangel, F.X. Bosch, N. Munoz and K.R. Cho, Somatic mutations of fibroblast growth factor receptor 3 (FGFR3) are uncommon in carcinomas of the uterine cervix, Oncogene 19(48) (2000), 5543-5546. 


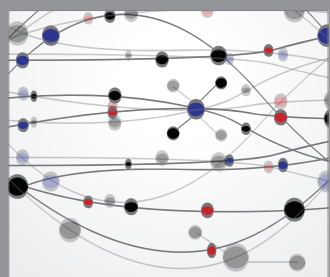

The Scientific World Journal
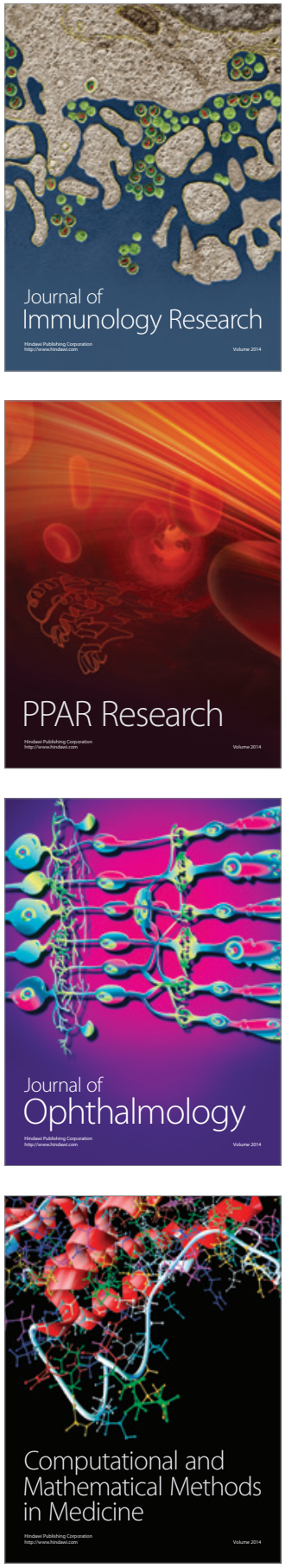

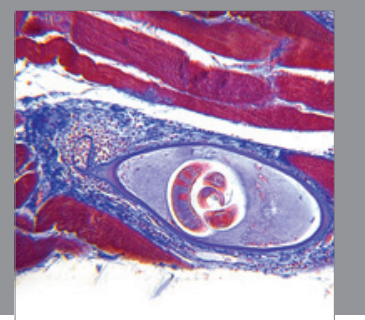

Gastroenterology

Research and Practice
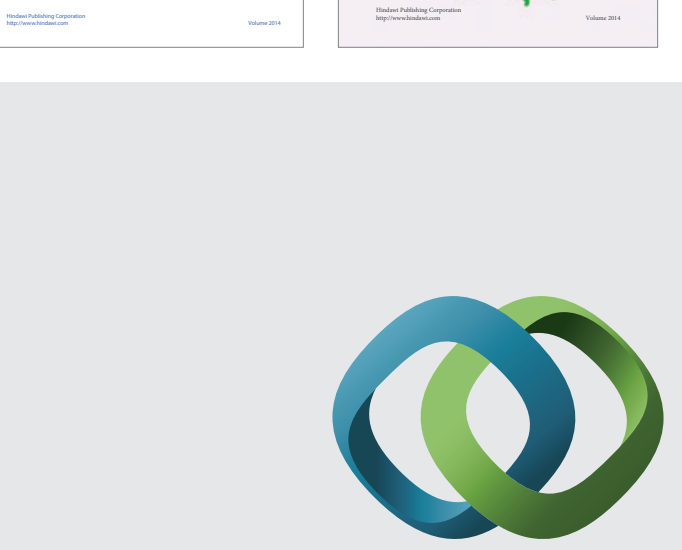

\section{Hindawi}

Submit your manuscripts at

http://www.hindawi.com
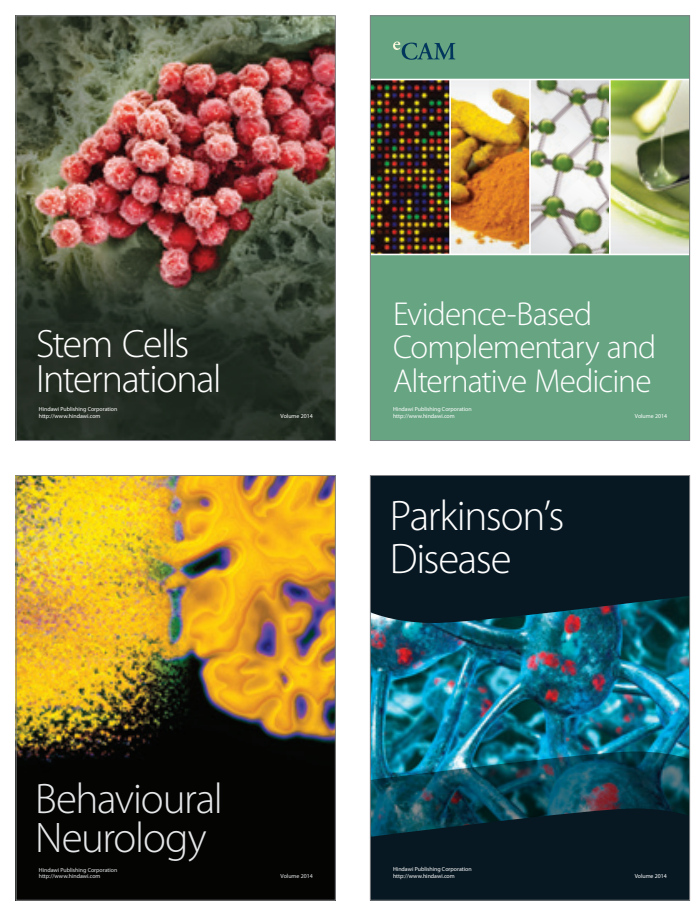

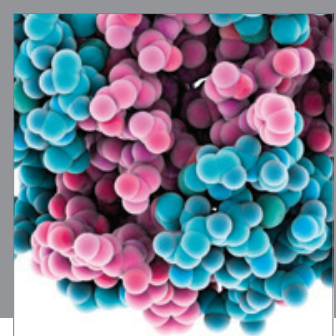

Journal of
Diabetes Research

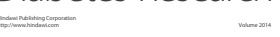

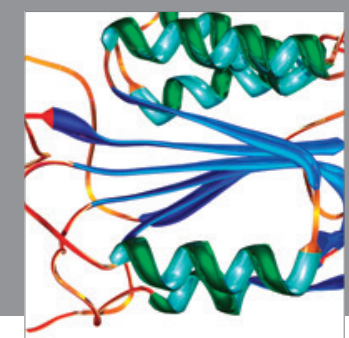

Disease Markers
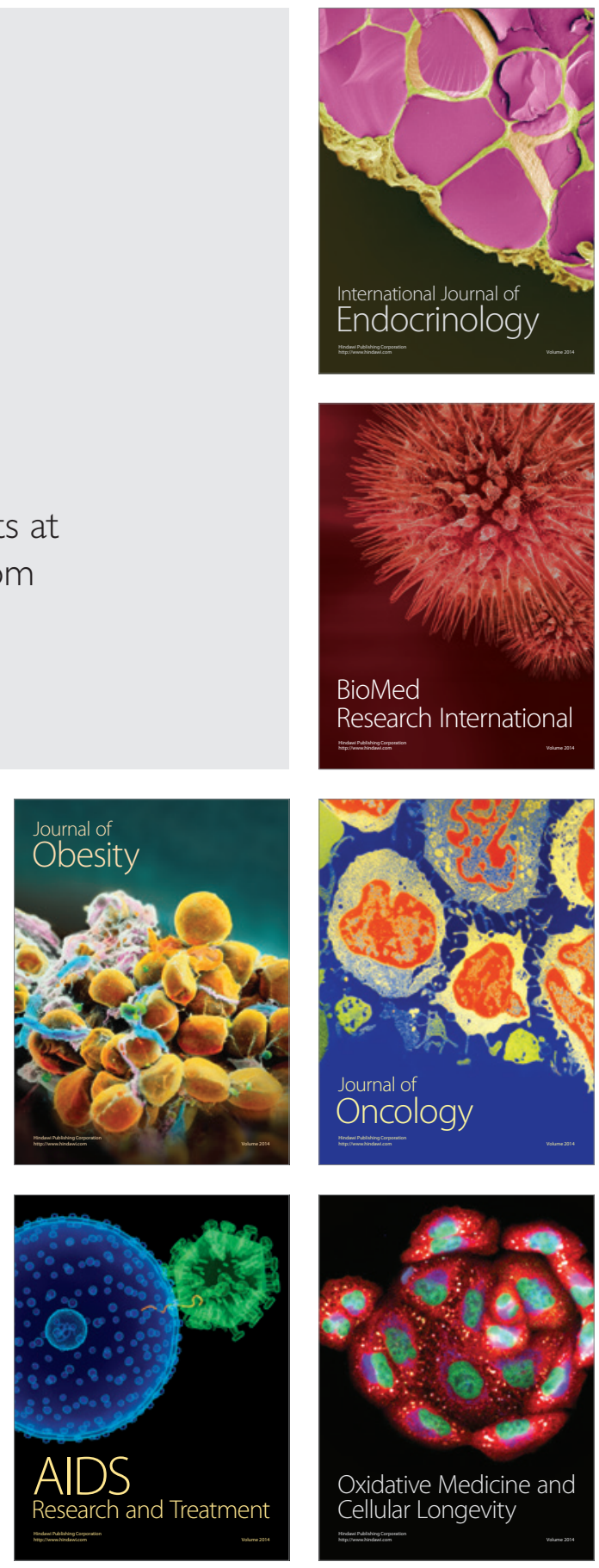